\title{
https://doi.org/10.1016/j.appdev.2019.101071
}

\section{Remarkable Cognitive Catch-Up in Chinese Adoptees Nine Years After Adoption}

Chloë Fineta ${ }^{\mathrm{a} b,}{ }^{*}$, Harriet J. Vermeer ${ }^{\mathrm{c}}$, Femmie Jufferc ${ }^{\mathrm{c}}$, Patricia Bijttebier ${ }^{\mathrm{d}}$, \& Guy Bosmans $^{\mathrm{b}}$

${ }^{a}$ Department of Psychology, New York University Abu Dhabi, P.O. Box 129188, Abu Dhabi, UAE

${ }^{\mathrm{b}}$ Clinical Psychology, KU Leuven, Tiensestraat 102 - bus 3720, Leuven 3000, Belgium

${ }^{c}$ Centre for Child and Family Studies, Leiden University, Pieter de la Court Building, Postbus 9555, 2333AK, Leiden, the Netherlands

d School Psychology and Child and Adolescent Development, KU Leuven, Tiensestraat 102 - bus 3717, 3000 Leuven, Belgium

* Corresponding author. E-mail: cf105@,nyu.edu, TEL: +97126284753

\author{
E-mail: \\ cf105@nyu.edu \\ vermeer@fsw.leidenuniv.nl \\ juffer@fsw.leidenuniv.nl \\ patricia.bijttebier@kuleuven.be \\ guy.bosmans@kuleuven.be
}




\title{
Remarkable Cognitive Catch-Up In Chinese Adoptees Nine Years After Adoption
}

\begin{abstract}
We investigated (1) whether 10-year-old internationally adopted Chinese girls who, on average, showed below-average intellectual functioning two and six months after adoption (Times 1-2, N=92), showed catch-up in intellectual functioning, school achievement, and executive functioning nine years later (Time $3, N=87$ ). We tested (2) effects of type of preadoption care (institutional versus foster care), and effects of parental sensitivity (factor score for supportive presence and for intrusiveness compiling all three time points), and we examined (3) whether the latter buffered the effects of type of care. The children showed significant recovery and complete catch-up in intellectual functioning at Time 3, and did not lag behind at school compared to non-adopted children. Contrary to the results of Times 1 and 2, type of care was not associated with cognitive development at Time 3. Parental sensitivity did not buffer the link between type of care and cognitive development.
\end{abstract}

Keywords. International adoption, type of pre-adoption care, intellectual functioning, school achievement, executive functioning, parental sensitivity 


\section{Remarkable Cognitive Catch-Up In Chinese Adoptees Nine Years After Adoption}

Prior to adoption, adopted children are often deprived of positive experiences (e.g., stable relationships with a sensitive caregiver, cognitive stimulation, good nutrition) that are necessary for optimal brain development (Nelson, Bos, Gunnar, \& Sonuga-Barke, 2011) and social-emotional wellbeing. This may increase their risk for delays in a broad range of outcomes, including cognitive development (Juffer \& Van IJzendoorn, 2009). After adoption, however, adopted children generally experience a drastic, positive change in living circumstances, which may provide opportunities to recover from early adverse experiences. Ample research has indeed shown that adopted children generally show recovery in their cognitive development following adoption, with considerable catch-up in some domains of cognitive development such as intellectual functioning (i.e., general mental capacity which is composed of multiple cognitive abilities such as abstract reasoning abilities and general knowledge), and remarkable but incomplete catch-up in other domains such as school achievement (for a meta-analysis, see Van IJzendoorn, Juffer, \& Klein Poelhuis, 2005) and executive functioning (i.e., self-regulatory processes that exert control over cognition, attention and behavior; Zhou, Chen, \& Main, 2012) (for overviews, see Finet, Vermeer, Juffer, Bosmans, \& Bijttebier, 2016; Merz, Harlé, Noble, \& McCall, 2016).

At the same time, research also points to substantial variability in adopted children's cognitive outcomes (e.g., Cohen, Lojkasek, Zadeh, Pugliese, \& Kiefer, 2008; Juffer, Van den Dries, Finet, \& Vermeer, 2015). Although some adopted children show complete recovery and catch-up in their cognitive development, other adopted children show more persistent delays (Palacios et al., 2019). Currently, there is a lack of knowledge about which factors may play a role in explaining this variability (Barroso, Barbosa-Ducharne, Coelho, Costa, \& Silva, 2017; Palacios \& Brodzinsky, 2010). Increasing knowledge on this issue is important 
because it may help to develop prevention or interventions programs aimed at improving adopted children's outcomes. Therefore, in addition to examining recovery and catch-up in adopted children's cognitive development, another aim of the study described in the current paper - the longitudinal Chinese Adoptees in the Netherlands (CAN) study - was to increase insight into factors that may account for variability in internationally adopted children's cognitive development. Using a risk and resilience theoretical approach (Masten, 2001; Rutter, 1987) we investigated the potential role that both risk factors (i.e., factors that increase the chance for children's poor outcomes) as well as protective factors (i.e., factors that may buffer the negative effects of risk factors) may play. We were specifically interested in type of pre-adoption care (institutional care versus foster care) as a candidate risk factor and in adoptive parenting as a candidate protective factor.

\section{Type of Pre-Adoption Care}

One factor that may be associated with variability in internationally adopted children's cognitive development relates to the heterogeneity in adopted children's preadoption experiences. Adopted children differ along many pre-adoption factors including, for instance, age at adoption - a proxy for length of exposure to pre-adoption deprivation and quality of pre-adoption care. Although age at adoption has been found to be an important variable in some studies (Van IJzendoorn et al., 2005), it has been argued that the quality of pre-adoption care might be more influential than age at adoption itself (Odenstad et al., 2008). In the current study we were therefore specifically interested in investigating the role of quality of pre-adoption experiences. One indicator of quality of pre-adoption experiences that may account for variability in adopted children's outcomes is the type of care that children have received prior to adoption. Whereas the majority of adopted children live in institutions prior to adoption, a minority of them lives in temporary foster families (Gunnar, Bruce, \& Grotevant, 2000). Although variability among institutions exists in quality of care 
and in the extent to which children's developmental needs are met (e.g., health, nutrition, stimulation and relationship needs; Rice, Jackson, Mahoney, \& Tan, 2016), a common characteristic of almost all institutions is that they do not provide children with the opportunity to build stable relationships with consistent caregivers. Institutions, for instance, are often characterized by large groups, high child-to-caregiver ratios, caregivers working in rotating shifts, and lack of individualized care, limiting opportunities to develop stable relationships. Consequently, institutionalized children are often deprived of "species typical caregiving experiences" (Tottenham, 2012), which may result in chronic stress and which may negatively impact the development of brain regions involved in cognitive functioning (Loman \& Gunnar, 2010). In contrast to institutional care, foster care is a type of family care and hence is designed to provide children with opportunities to build relationships with consistent caregivers. Moreover, not only children's needs for stable relationships, but also other developmental needs are more likely to be met in foster care. It, thus, can be expected that foster care will be less detrimental than institutional care for internationally adopted children's development. Nonetheless, there is a scarcity of research in which the hypothesized differential effects of pre-adoption institutional care versus foster care on adopted children's cognitive development is investigated.

Therefore, the longitudinal CAN study, in which 92 girls adopted from China to the Netherlands participated, was set up to compare children adopted from institutional care with children adopted from foster care (see also Finet, Vermeer, Juffer, Bijttebier, \& Bosmans, 2019; Van den Dries, Juffer, Van IJzendoorn, \& Bakermans-Kranenburg, 2010; Van den Dries, Juffer, Van IJzendoorn, Bakermans-Kranenburg, \& Alink, 2012). In line with expectations, results of the first two time points of the CAN study, which took place two (Time 1) and six months (Time 2) after adoption at a mean age of 13.03 months $(S D=1.35)$, revealed that the post-foster children (Time 1: $M=84.40, S D=17.62$, Time $2: M=92.26, S D$ 
$=17.83$ ) had better intellectual abilities than the post-institutionalized children (Time 1: $M=$ 74.04, $S D=18.41$, Time 2: $M=84.38, S D=20.01$; Van den Dries et al., 2010). Moreover, results demonstrated that both the post-institutionalized as well as the post-foster children had below-average intellectual abilities at the first two time points, although they showed significant recovery between the first and second time point. In the current paper we aimed to investigate whether the differential effects of type of pre-adoption care on cognitive development were still present nine years after adoption, at the age of 10 years (Time 3). Moreover, we aimed to investigate whether the children showed further recovery in intellectual functioning since Time 2, and whether they showed complete catch-up in their cognitive development compared to non-adopted children.

The few other studies that have examined associations between type of pre-adoption care and cognitive development have yielded mixed evidence, with some studies finding significant effects of type of pre-adoption care on various domains of cognitive development such as intellectual functioning (Miller, Chan, Comfort, \& Tirella, 2005; van Londen, Juffer, \& Van IJzendoorn, 2007; Wilson, Weaver, Cradock, \& Kuebli, 2008), school achievement (Loman, Wiik, Frenn, Pollak, \& Gunnar, 2009) and executive functioning (Bruce, Tarullo, \& Gunnar, 2009), and other studies not finding effects (e.g., Katzenstein, LeJeune, \& Johnson, 2016; Pollak et al., 2010; Welsh \& Viana, 2012). In line with research on the effects of other adverse experiences, these inconsistent findings regarding the impact of type of pre-adoption care may suggest that its effects are not deterministic (Sroufe, Coffino, \& Carlson, 2010) nor permanent (Smith et al., 2018). One possible explanation which may explain why some children are more affected by adverse experiences prior to adoption than other children, comes from risk and resilience theory (Masten, 2001; Rutter, 1987). According to this theoretical approach the negative effects of risk factors (e.g., institutional care) can be counteracted by protective factors. One possible, but understudied, protective factor that may 
moderate the effects of type of care is parenting in the adoptive family (Benzies \& Mychasiuk, 2009; Juffer et al., 2011).

\section{Adoptive Parenting}

Parenting is a core influence in a child's life. Although parents may differ on various parenting dimensions, according to attachment theory (Bowlby, 1982) one parenting dimension which is particularly important for promoting positive child outcomes is parental sensitivity. This parenting dimension refers to parents' ability to perceive their child's signals, to interpret these signals correctly, and to timely and adequately respond to these signals (Ainsworth, Blehar, Waters, \& Wall, 1978). In line with these theoretical predictions, numerous studies in non-adopted children have shown that parental sensitivity is predictive of positive outcomes in different developmental domains, including the cognitive domain (e.g., Bernier, Carlson, \& Whipple, 2010; Cabrera, Shannon, \& Tamis-Lemonda, 2007; Downer \& Pianta, 2006; Fay-Stammbach, Hawes, \& Meredith, 2014; Lugo-gil \& Tamis-lemonda, 2008; Ryan, Martin, \& Brooks-Gunn, 2006). In addition to the direct impact of parental sensitivity on child outcomes, gradually emerging evidence from non-adopted children also yields support for indirect, buffering effects of parental sensitivity (Benzies \& Mychasiuk, 2009). Landry, Smith, Swank, Assel, and Vellet (2001), for instance, found that parental sensitivity acted as a protective factor in the association between preterm birth and cognitive functioning. Preterm children showed comparable growth in cognitive functioning over time - from age 6 months to age 54 months - as full-term children, but only when their mothers were consistently sensitive over time. Sensitivity thus buffered the association between preterm birth and cognitive functioning (Landry et al., 2001). These studies in non-adopted children provide support for a protective role of parental sensitivity for non-adopted children's cognitive development. 
Relatively few adoption studies have examined the effects of parental sensitivity, or parenting more generally, on adopted children's cognitive development. Nevertheless, adoption studies in which the association between other aspects of the parent-child relationship, such as parent-child relationship quality, and cognitive development have been studied, generally find evidence for such associations (e.g., Groza, Ryan, \& Thomas, 2008; Whitten \& Weaver, 2010). Moreover, an adoption study that did investigate the effect of parental sensitivity found that sensitivity was associated with better cognitive development in 7-year-old internationally adopted children (Stams, Juffer, \& Van IJzendoorn, 2002). This study points to the importance of parental sensitivity for adopted children's cognitive functioning. This evidence together with the variability in adopted children's cognitive outcomes following early adverse experiences (such as institutional care), suggest that parenting may moderate the association between type of pre-adoption care (institutional versus foster care) and cognitive development. However, as far as we know, to date no studies have examined this hypothesis. Hence, another aim of the current study was to examine whether parental sensitivity moderated the association between type of pre-adoption care and adopted children's cognitive functioning.

\section{The Current Study}

Using a risk and resilience theoretical approach, we aimed (1) to examine whether the 10-year-old children who took part in the third time point of the longitudinal CAN study showed further recovery in their intellectual functioning since Time 2 and whether they showed complete catch-up in their cognitive development compared to non-adopted children. Furthermore, we aimed (2) to study the associations between type of pre-adoption care and cognitive development, and (3) to examine whether parental sensitivity buffered against the effects of type of pre-adoption care. To obtain a broad understanding of children's current cognitive functioning, we assessed multiple domains of cognitive development, namely 
intellectual functioning, school achievement in mathematics and in reading comprehension, and two aspects of executive functioning (executive problem-solving and response inhibition). It should be noted that the research question concerning recovery was only investigated with respect to intellectual functioning, and the research question concerning catch-up was only investigated with respect to intellectual functioning and school achievement, because no normative data was available for the tests that were administered to measure executive functioning.

Based on previous studies with children adopted from China (Cohen et al., 2008; Dalen \& Rygvold, 2006; Delcenserie, Genesee, \& Gauthier, 2013), we hypothesized that the children would show significant recovery between Time 2 and Time 3 in intellectual functioning. Moreover, we expected that on average the children would show complete catch-up in intellectual functioning and would do as well at school as the general population. Furthermore, we predicted that type of pre-adoption care would be associated with the children's cognitive development, with the post-foster children outperforming the postinstitutionalized children. Finally, we hypothesized that the effects of type of pre-adoption care on the different domains of cognitive development would depend upon parental sensitivity, with high parental sensitivity buffering against the negative effects of preadoption institutional care.

As noted above, the research questions were examined in a sample of children adopted from China - the number one birth country of internationally adopted children in previous years (Selman, 2015). The main reason why many children in China, especially healthy infant girls, were abandoned, were the strictly enforced birth planning policies (e.g., one-child policy and one-son-two-children policy) which were in place from 1979 until recently (Hesketh, Zhou, \& Wang, 2015). As a result of these specific circumstances leading to adoption from China, Chinese adoptees were less likely to have experienced pre- and 
perinatal adversities (such as maternal alcohol or drug abuse) compared to children adopted from many other countries (e.g., Eastern Europe; Landgren, Svensson, Strömland, \& Grönlund, 2010). This has the advantage that it allows investigating the effects of adoption and of type of pre-adoption care while controlling for possible effects of early adverse experiences in the birth family. At the same time, however, it is important to acknowledge that results of our study may lack generalizability to other groups of internationally adopted children because of these unique circumstances surrounding adoption from China and because nowadays there is a shift towards adoption of children with special needs (Selman, 2015).

\section{Method}

\section{Participants and Procedure}

Participants of the CAN study were 92 girls adopted from China to the Netherlands at a mean age of 13.03 months $(S D=1.35$, range $=10.84-16.53)$. The Dutch adoption organizations mediating adoption from China to the Netherlands helped recruit the families (see Van den Dries et al., 2010; 2012). The 92 families took part in the first two time points of the study, two months (Time 1) and six months (Time 2) after adoption, and 87 families participated in the third time point at the child's age of 10 years, nine years after adoption (Time 3). The major reason for non-participation at Time 3 were time constraints. However, four families who dropped out at Time 3 were willing to complete an online background questionnaire $(n=91)$, and to provide information on the school performance (CITO scores, see below) of their daughter $(n=89)$. CITO scores of two children who participated at Time 3 were missing, because one family did not give their informed consent to provide their child's CITO scores, and because one family migrated to New Zealand where Dutch CITO scores are not being used. 
Each time point consisted of a home visit and a laboratory visit at Leiden University. The girls took part in the study together with their primary caregiver $(90$ mothers and 2 fathers at Time 1 and Time 2; 81 mothers, 3 fathers, and 3 girls who participated with their mother at one of the visits and with their father at the other visit at Time 3), whom we will refer to as mother. Mean education at Time 3 of the primary and the secondary caregiver on a scale from 1 (primary school) to 5 (university) was $3.92(S D=0.93)$ and $4.10(S D=0.88)$ respectively. The girls were on average $15.24(S D=1.35)$ and $15.66(S D=1.42)$ months old at the Time 1 home and university visit, $19.33(S D=1.40)$ and $19.85(S D=1.48)$ months old at the Time 2 visits, and $119.72(S D=5.23)$ and $122.07(S D=5.57)$ months old at the Time 3 visits. In infancy (Time 1 and Time 2) parents gave their informed consent for participation in the study, and at Time 3 both the parents and the girls gave their informed consent. The Ethics Review Board of the Faculty of Social Sciences of Leiden University approved the follow-up study (ECPW-2014/067).

\section{Measures}

Type of pre-adoption care. At Time 1 mothers reported whether their child had lived in institutional care or foster care in China. This information was used to classify the children in the post-institutionalized or in the post-foster group (see Van den Dries et al., $2010 ; 2012)$. Children in the post-institutionalized group $(n=50)$ had mainly experienced institutional care before adoption $(M=12.44$ months, $S D=1.36)$ and a maximum of one month of other forms of care such as foster care $(M=0.65$ months, $S D=0.59)$. The postfoster group consisted of children who had exclusively lived in foster care prior to adoption $(n=16)$ and children who had lived in both foster care as well as institutional care $(n=26)$. The post-foster children $(n=42)$ had on average lived 9.32 months $(S D=3.55$, range 1.44$14.85)$ in foster care and 3.65 months $(S D=3.86$, range $0-14)$ in institutional care. 
Parental sensitivity: supportive presence and lack of intrusiveness. At each time point video recordings of problem-solving tasks in which mother and child engaged were coded for supportive presence and intrusiveness with the Erickson scales (Egeland, Erickson, Clemenhagen-Moon, Hiester, \& Korfmacher, 1990; Erickson, Sroufe, \& Egeland, 1985). These two Erickson scales were used as indicators of parental sensitivity, with higher supportive presence and lower intrusiveness indicative of higher sensitivity. Supportive presence refers to the extent to which mother expresses emotional support and positive regard to her child and lets her child know that she has confidence in her child's competence. Intrusiveness refers to the degree to which mother interferes with her child's autonomy and exploration in the task, and to which she exerts her own expectations on her child. Both scales were rated on a seven-point scale ranging from 1 (very low) to 7 (very high). At Times 1 and 2 supportive presence and intrusiveness were observed at the university during two problem-solving tasks of 4 min each, and at Time 3 supportive presence and intrusiveness were assessed at home during a 10 min tangram puzzle solving task. To prevent possible learning effects to occur across the three time points, parents received no feedback on their parenting behavior after the observations and remained unaware of the purpose of the task. The more verbal nature of mother-child interactions in middle childhood, compared to the more physical interactions in infancy, was taken into account in the coding of supportive presence and intrusiveness at Time 3 (convergent with Stams et al, 2002). Different coders coded the Time 1, Time 2 and Time 3 assessments of the same family. The interrater reliability (intraclass correlation) with the expert coder (FJ) was $>.70$ at Time 1 and Time 2 for both scales. At Time 3 the intraclass correlation (two-way mixed, single measure) of the single rater with the expert coder (FJ) was .92 for supportive presence, and .96 for intrusiveness $(n=15)$. 
Intellectual functioning. In infancy (Times 1 and 2) the intellectual abilities of the children were assessed during the home visit with the Dutch version of the second edition of the Bayley Scales of Infant Development (BSID-II-NL; Van der Meulen, Ruiter, Lutje Spelberg, \& Smrkovsky, 2004). The BSID-II-NL is a standardized assessment instrument used to measure the mental and psychomotor development of children aged between 1 and 41 months. For the current analyses, only the mental scale was used. Raw scores on this scale were converted to age-corrected standard scores $(M=100, S D=15)$.

At Time 3 two broad cognitive abilities were assessed, namely crystallized intelligence and fluid intelligence. These two cognitive abilities have the highest loadings on general intelligence according to the Cattell-Horn-Carroll (CHC) theory of cognitive abilities (Alfonso, Flanagan, \& Radwan, 2005). To assess crystallized intelligence (i.e., culturally acquired knowledge; Cattell, 1971) the information (general knowledge questions) and vocabulary subtest (defining words) of the Dutch Wechsler Intelligence Scale for ChildrenThird Edition (WISC-III-NL; Kort et al., 2005; Wechsler, 1991) were administered. Raw scores on both subtests were converted to age-corrected standardized scores which were transformed into an IQ score (Sattler, 1992). To get an indication of children's general reasoning ability (an aspect of fluid intelligence; Cattell, 1971), the analogies (reasoning by analogy) and categories (reasoning by categorization) subtests of the Snijders-Oomen NonVerbal Intelligence Test (SON-R 6-40; Tellegen \& Laros, 2011) were administered. Raw scores on both subtests were transformed to age-corrected standardized scores which were used to estimate total cognitive performance on the SON-R 6-40.

School achievement. At Time 3, mothers asked their child's teacher to provide their child's most recent, standardized scores on the school tests developed by the Dutch National Institute for Educational Measurement (CITO). These CITO tests are the nationwide standardized tests of school achievement in the Netherlands, and performance on these tests 
indicate how well a child does at school compared to the norm group of Dutch children in the same grade. CITO-scores with respect to mathematics and with respect to reading comprehension were obtained. Two different classifications exist, namely an A-E classification $(A=25 \%$ highest scoring children, $B=25 \%$ children scoring a lot or somewhat higher than average, $\mathrm{C}=25 \%$ children scoring somewhat or a lot lower than average, $\mathrm{D}=$ $15 \%$ children scoring a lot lower than average, $\mathrm{E}=10 \%$ children with the lowest scores) and a $I-V$ classification $(I=20 \%$ highest scoring children, $I I=20 \%$ children scoring above average, III $=20 \%$ average scoring children, IV $=20 \%$ children scoring below average, $\mathrm{V}=$ $20 \%$ children with the lowest scores). Because teachers provided CITO scores using the I-V classification for the majority of children $(n=75)$, we used this classification in the current analyses. We transformed the A-E classification to the I-V classification for the 14 children for whom only the A-E classification was provided (A classified as I, B as II, C as IV, and D and $\mathrm{E}$ as V). The I-V classifications for mathematics (I: $31.5 \%$, II: 20.2\%, III: $19.1 \%$, IV: 16.9\%, V: 12.4\%) and for reading comprehension (I: $37.1 \%$, II: $27 \%$, III: $13.5 \%$, IV: $14.6 \%$, V: $7.9 \%$ ) were coded as $1-5$ in the current analyses with lower scores indicating better math performance and better reading comprehension (compared to the norm). Scores were $\log 10$ transformed to reduce positive skewness (mathematics: $M=0.34, S D=0.26$, range 0.00 0.70 ; reading comprehension: $M=0.29, S D=0.25$, range $0.00-0.70$ ).

Executive functioning: problem-solving efficiency. During the Time 3 home visit, the Tower of London-Drexel task (TOL ${ }^{\mathrm{DX}}$; Culbertson \& Zillmer, 1998) was administered to measure executive problem-solving. In this test the child has to move three colored beads across three pegs of descending height in order to copy the examiner's goal configuration. The TOL ${ }^{\mathrm{DX}}$ consists of 15 test problems which need to be solved in as few as moves as possible without moving more than one bead at a time and without placing more beads on the pegs than they can hold. In the current analyses the variable total move score (i.e., the sum of 
the observed number of moves exceeding the minimally required moves on the 15 test problems) was used. This variable can be seen as an indicator of problem-solving efficiency (Berg \& Byrd, 2002), with higher move score reflecting lower problem-solving efficiency. If the observed number of moves on a test problem exceeded 20, it was rounded down to 20 to avoid inflation of the total move score (Culbertson \& Zillmer, 1998). Administration of the $\mathrm{TOL}^{\mathrm{DX}}$ was videotaped for later coding.

Executive functioning: response inhibition. A stop-signal task (SST), programmed by Verbruggen, Logan, and Stevens (2008), was administered to the children at the Time 3 university visit to assess response inhibition. The SST consists of no-signal trials $(75 \%$ of the trials) and stop-signal trials (25\% of the trials). On the no-signal trials, children have to discriminate between two primary-task stimuli displayed in the center of the screen, as fast and accurately as possible by pressing the correct button on the key board. On the stop-signal trials, presentation of the primary-task stimulus is followed by an auditory stop signal instructing the participants to inhibit their response. The delay between the onset of the primary-task stimulus and the onset of the stop signal (i.e., the stop signal delay; SSD) is continuously adjusted (see Verbruggen et al., 2008) to ensure that all children inhibit their response successfully on approximately $50 \%$ of the stop-signal trials. The average SSD in the current study was $359.67 \mathrm{~ms}(S D=131.50)$.

In the current analyses the variable stop signal reaction time (SSRT) was used, which refers to the time it takes to inhibit a response (Logan, Van Zandt, Verbruggen, \& Wagenmakers, 2014). The lower the child's SSRT, the better the child's response inhibition. We computed SSRT using the integration method (Verbruggen, Chambers, \& Logan, 2013) and excluded the children $(n=11)$ who did not meet the criteria necessary for a reliable estimation of SSRT (see Congdon et al., 2012; Verbruggen \& Logan, 2015) from the 
analyses in which SSRT was used. Because SSRT was positively skewed, we took the square root of SSRT $(M=15.94, S D=2.08$, range 11.52-21.33).

\section{Data-Analysis}

Prior to main analyses, two principal component analyses were performed to create a longitudinal compound score for Times 1-3 supportive presence and for Times 1-3 intrusiveness. In both principal component analyses, one factor was extracted based on Kaiser's criterion of retaining factors with eigenvalues greater than one. The supportive presence factor $(M=0, S D=1$, range from -2.27 to 2.07$)$ - reflecting the common variance between the supportive presence scores at the three time points - had an eigenvalue of 1.71 and explained $56.97 \%$ of total variance in the three supportive presence scores. The loadings of Time 1, Time 2 and Time 3 supportive presence on this factor were $.77, .76$, and .73 . The intrusiveness factor $(M=0, S D=1$, range from -1.91 to 2.58) had an eigenvalue of 1.60 and explained $53.12 \%$ of total variance in the intrusiveness scores. The loadings of the intrusiveness scores on this factor were .82 for Time $1, .76$ for Time 2, and .58 for Time 3 intrusiveness.

To investigate the research question concerning recovery in the children's intellectual functioning since Time 2, two repeated measures analyses were performed with crystalized intelligence and fluid intelligence as outcome variables. In both analyses Time 1 intellectual functioning was included as covariate and type of pre-adoption care was included as between-subject factor. To investigate whether the children in our study showed complete catch-up in intellectual functioning compared to non-adopted children, two one-sample $t$-tests were performed to compare mean crystallized and mean fluid intelligence of the children in our study with the standardized IQ mean of $100(S D=15)$. A Chi-square goodness-of-fit test was performed for math performance and for reading comprehension, to examine whether the distribution of children in our sample in each of the five school performance classification 
levels (I-V) differed from the general population distribution (equal proportion of children [namely 20\%] in each category). To answer our research question concerning the effect of type of care on cognitive development, an independent sample $t$-test was performed for each of the six cognitive outcomes.

To investigate the research question concerning the buffering effect of parental sensitivity (supportive presence and intrusiveness) in the association between type of preadoption care and the six outcomes, 12 moderation analyses were performed using the PROCESS macro in SPSS (Hayes, 2013). To control for inflation of type I error due to multiple testing, a Bonferonni corrected significance value of $.004(=.05 / 12)$ was applied. In the moderation analyses for intellectual functioning (crystallized and fluid intelligence) we controlled for Time 1 intellectual abilities, to test whether the interactions predicted additional variance in Time 3 intellectual functioning over and above the variance explained by Time 1 intellectual abilities. To increase interpretability of the interaction terms a dummy variable was computed for type of pre-adoption care $(0=$ post-institutionalized group, $1=$ post-foster group). Next, we conducted supplementary moderation analyses to test whether the results of the main analyses still held after controlling for some other factors that may be related to cognitive development. Specifically, we controlled for age at adoption (e.g., Van IJzendoorn et al, 2005), head circumference measured at Time 3 (Pomerleau et al., 2005), and maternal education at Time 3 as indicator of SES (e.g., Plug \& Vijverberg, 2003).

In total there was $3.1 \%$ of data missing on all variables. Based on Little's MCAR test it was assumed that the data were missing completely at random, $\chi^{2}(188)=215.74, p=.081$. Missing data were listwise deleted. 


\section{Results}

\section{Preliminary Analyses}

Descriptive statistics of the model variables are presented in Table 1 for the postinstitutionalized children, the post-foster children and the total sample. There were no significant group differences between the post-institutionalized and the post-foster children on the parenting variables, with one exception. Parents of the post-institutionalized children scored significantly lower on supportive presence at Time 1 than parents of the post-foster children. In Table 2 the correlations between the variables are shown. Supportive presence correlated positively with fluid intelligence, indicating that children whose mothers were more supportive performed better on the test used to assess fluid intelligence. No other significant correlations between the parenting variables and cognitive functioning were found. Furthermore, there were no significant associations between Time 1 and Time 2 intellectual abilities on the one hand and Time 3 cognitive functioning on the other hand, with the exception of a significant, positive association between Time 1 intellectual abilities and Time 3 fluid intelligence. Several measures of Time 3 cognitive functioning were significantly correlated with each other (see Table 2).

\section{Recovery in Intellectual Functioning}

Results of the repeated measures analysis for crystallized intelligence and fluid intelligence indicated that, controlling for Time 1 intellectual abilities, the postinstitutionalized and post-foster children showed significant recovery in intellectual functioning since Time 2 (crystallized intelligence: $F(1,84)=60.17, p<.001, \eta^{2} p=.417$; fluid intelligence: $\left.F(1,84)=25.43, p<.001, \eta^{2} p=.232\right)$. The extent of recovery in intellectual functioning did not differ between the post-institutionalized and the post-foster 
children (crystallized intelligence: $\mathrm{F}(1,84)=0.76, p=.386, \eta^{2}{ }^{2}=.009$; fluid intelligence: $\mathrm{F}(1$, $\left.84)=0.82, p=.368, \eta^{2}=.010\right)$.

\section{Catch-Up in Intellectual Functioning and School Achievement}

Comparison of the Time 3 mean intellectual functioning of the children in our sample with the standardized IQ mean of $100(S D=15)$ indicated that the adopted children scored significantly higher on crystallized intelligence, $t(86)=8.38, p<.001, d=0.90$, and on fluid intelligence, $t(86)=5.29, p<.001, d=0.57$. Similar findings were found for the postinstitutionalized (crystalized intelligence: $t(45)=6.12, p<.001, d=0.90$; fluid intelligence: $t(45)=3.73, p<.001, d=0.55)$ and the post-foster children (crystalized intelligence: $t(40)=$ 5.67, $p<.001, d=0.89$; fluid intelligence: $t(40)=3.72, p<.001, d=0.58$ ) separately. Mean intellectual functioning of the post-institutionalized and the post-foster children at each time point are depicted in Figure 2.

Comparison of the distribution of the adopted children in the school performance classification levels with the general population distribution $(20 \%[n=18]$ children in each category), revealed that the distributions did not differ significantly for math performance, $\chi^{2}$ (4) $=8.92, p=.063$, but did differ significantly for reading comprehension, $\chi^{2}(4)=24.88, p<$ .001. There appeared to be more adopted children in the highest classification levels (I: $n=$ 33, II: $n=24$ ) and fewer adopted children in the average and below-average classification levels (III: $n=12$, IV: $n=13, \mathrm{~V}: n=7$ ) than predicted based on the general population distribution $(n=18)$. Similar findings were found for the post-institutionalized and the postfoster children separately (math performance: post-institutionalized $\chi^{2}(4)=5.75, p=.219$, post-foster $\chi^{2}(4)=3.76, p=.440$; reading comprehension: post-institutionalized $\chi^{2}(4)=$ $14.71, p=.005$, post-foster $\left.\chi^{2}(4)=11.32, p=.023\right)$. In sum, the adopted children showed complete catch-up in intellectual functioning and did as well at school compared to nonadopted children. 


\section{Associations Between Type of Pre-Adoption Care and Cognitive Development}

At Time 3, the post-institutionalized children and the post-foster children did not differ in their performance on the two intelligence tests (crystallized intelligence: $t(85)=$ $0.34, p=.738$; fluid intelligence: $t(85)=-0.08, p=.934)$, nor in their school achievement (mathematics: $t(87)=-0.46, p=.647$; reading comprehension: $t(87)=-0.00, p=.997$ ), nor in their performance on the two executive functioning tasks (problem solving efficiency: $t(85)=$ $-0.40, p=.693$; response inhibition: $t(73)=0.86, p=.393$ ). Thus, contrary to expectations, at age 10 there were no significant differences between the post-institutionalized and the postfoster children on the different indices of cognitive development (see Table 1). ${ }^{1}$

\section{Type of Pre-Adoption Care X Parental Sensitivity Interactions}

Using the Bonferroni corrected significance value of .004, no significant interactions between type of pre-adoption care and parental sensitivity (supportive presence or intrusiveness) in the prediction of the six different cognitive outcomes were found (see Table $3)^{2}$ Similar non-significant results were found when controlling for age at adoption, Time 3 head circumference and Time 3 maternal education.

\section{Discussion}

The current study is part of the longitudinal CAN study that started in infancy. Using a risk and resilience theoretical approach, we examined the cognitive functioning of 87 girls adopted from institutional care or foster care in China - at the age of 10 , nine years after their adoption. We aimed (1) to study whether the adopted children who, on average, showed below-average intellectual functioning in infancy showed recovery in intellectual functioning and complete catch-up in intellectual functioning and school achievement at age 10, (2) to investigate whether type of pre-adoption care was associated with the children's cognitive development, and (3) to investigate whether parental sensitivity moderated this hypothesized 
association. In line with theoretical expectations, we found that the adopted children after their initial delays in infancy showed resilience by displaying further recovery and complete catch-up in intellectual functioning, while they did at least as well at school as non-adopted children. Contrary to expectations, however, and in contrast to the assessments in infancy, no significant differences in cognitive development were found between the postinstitutionalized and the post-foster children. Furthermore, no evidence was found for a buffering effect of parental sensitivity after adoption.

\section{Recovery and Catch-Up in Cognitive Development}

In line with the results of the first two time points of the CAN study concerning the adopted children's recovery in intellectual functioning (Van den Dries et al., 2010), the third follow-up of the CAN study revealed that the children showed further recovery in intellectual functioning since Time 2. This result confirms findings from previous adoption studies demonstrating that adopted children, despite initial delays, display remarkable progress in their cognitive functioning after adoption (e.g., Cohen et al., 2008; O’Connor, Rutter, Beckett, Keaveney, \& Kreppner, 2000; Rutter \& the ERA study team, 1998; Stams, Juffer, Rispens, \& Hoksbergen, 2000; Vorria et al., 2006). In addition, the CAN study adds to these previous studies because, as far as we know, it is the first to longitudinally follow up the cognitive functioning of Chinese adopted children from infancy to middle childhood (Juffer et al., 2015). Some caution is warranted, however, in interpreting this result because intellectual functioning at Times 1 and 2 and at Time 3 was assessed with tests which are not necessarily directly comparable. The skills that are assessed by the Bayley scales which were administered at Time 1 and Time 2, are not necessarily predictive of performance on tests that are designed to assess intellectual functioning in older children, such as the WISC-III-NL and the SON-R 6-40 (Mackintosh, 1998). Despite this, we consider it a strong point that we made use of age-appropriate, standardized tests to assess intellectual functioning at the three 
time points, which enabled us to compare the mean intellectual functioning of the children in our study with the mean intellectual functioning of the normative population of non-adopted children. This comparison showed that - although intellectual functioning of adopted children lagged behind the norm group of non-adopted children at Times 1 and 2 - the adopted children caught up to the norm at Time 3 . This result concerning the adopted children's complete catch-up in intellectual functioning is in line with the meta-analysis of Van IJzendoorn et al. (2005) on cognitive functioning of adopted children showing that adopted children show normative intellectual functioning.

It is noteworthy that the adopted children in our study, on average, even showed above-average IQ scores. Similar findings of above-average intellectual functioning among internationally adopted children have also been reported in several previous studies, especially with South Korean adoptees (e.g., Frydman \& Lynn, 1989; Stams et al., 2000). Stams and colleagues (2000) suggested that this might point to high cognitive stimulation provided by adoptive families. Another alternative explanation lies in the main reasons for child abandonment and in the related differences in prenatal experiences. Because the majority of Chinese children were adopted due to the Chinese birth planning policies and because many Korean adoptees were adopted because of the stigma associated with unwed motherhood in South Korea, it is likely that they have experienced less prenatal adversities (e.g., prenatal alcohol or drug exposure) than children adopted from other countries, for example, Eastern European countries (e.g., Landgren et al., 2010). It may, hence, be important for adoption practitioners and adoptive parents to be informed about the specific circumstances leading to child abandonment and adoption in different birth countries. Nonetheless, when interpreting the favorable intellectual functioning, it is important to keep two points in mind. First, due to time constraints we only administered a brief intelligence battery consisting of two subtests that tap into fluid intelligence and two subtests that measure 
crystallized intelligence. Although these two broad cognitive abilities load highly on general intelligence, other broad cognitive abilities (e.g., visual information processing, processing speed) should be measured as well to ensure a valid and thorough assessment of intellectual functioning and to be able to estimate a total IQ score. Second, the Flynn effect (i.e., the general increase in performance on intelligence tests over generations resulting in norm obsolescence; Flynn, 1987; Trahan, Stuebing, Fletcher, \& Hiscock, 2014) might have overestimated the IQ scores of the children to some extent, because the norms of the WISCIII-NL have not been updated since 2000 and the norms of the SON-R 6-40 not since 2010. It has been estimated that there is an average yearly increase in crystallized intelligence of 0.21 IQ points and in fluid intelligence of 0.41 IQ points (Pietschnig \& Voracek, 2015). However, even when controlling for the Flynn effect, the adopted children still scored above average on the tests.

The adopted children also showed normative school performance in mathematics and better school performance in reading comprehension than the general population. This contradicts to some extent with the results of the meta-analyses of Van IJzendoorn et al. (2005) in which it was found that adopted children, despite their complete catch-up in intellectual functioning, performed somewhat less well at school than non-adopted children. This contrasting finding may be explained by the fact that in the meta-analyses no studies on Chinese adopted children - who probably have experienced less prenatal adversity than adopted children from many other countries - were included. Indeed, some previous adoption studies with Chinese adopted children have shown that these children do as well at school as non-adopted children (e.g., Dalen \& Rygvold, 2006). Another possible explanation for this contrasting finding may lay in the use of standardized scores for the assessment of school achievement in our study. It has been found that individual differences in performance on standardized CITO tests reflect to a large extent individual differences in intellectual 
functioning (Bartels, Rietveld, Van Baal, \& Boomsma, 2002). Hence, it might be that performance on CITO-tests are less subject to environmental effects (such as adoption-related socioemotional difficulties, teacher judgement) than performance on non-standardized school tests (e.g., school results, homework). This might explain why in the CAN study results for school achievement were similarly positive as results for intellectual functioning, whereas in the meta-analysis a small gap between school achievement and intellectual functioning was found.

\section{Associations Between Type of Pre-Adoption Care and Cognitive Development}

Another remarkable finding is that the differential effects of type of pre-adoption care on intellectual functioning that were found in the first months after adoption (Van den Dries et al., 2010) had disappeared nine years after adoption. At age 10, there were no significant differences between the post-institutionalized and the post-foster children in their performance on the intelligence tests, nor in the other domains of cognitive development. This finding suggests that with sufficient time in the adoptive family the post-institutionalized children were able to catch up with the post-foster children (due to the improved circumstances after adoption). Although this result points to children's resilience to overcome the effects of early adversities, it should not lead to the conclusion that type of preadoption care does not matter for the long-term development of adopted children, because the negative impact of being raised in institutional care has been robustly demonstrated in previous studies (Dozier et al., 2014; Van IJzendoorn et al., 2011). One possible explanation for our finding may be that the conditions in the Chinese institutions were not extremely depriving at the time of the study. However, the fact that in the first months after adoption a significant effect of type of care on intellectual abilities was found, contradicts this explanation to some extent. Furthermore, one could argue that the lack of significant effects of type of pre-adoption care at Time 3 might be explained by the fact that the post-foster 
group did not only include children who had exclusively lived in foster care prior to adoption, but also children who had experienced a combination of foster and institutional care. This might have made it more difficult to find type of care effects. However, additional analyses in which the exclusive foster care group and the mixed care group were treated separately did not alter the results. Moreover, in a large-scale study on the behavioral adjustment of internationally adopted Chinese children, in which the exclusive foster care group and the mixed care group were each compared separately with the post-institutionalized group, also no evidence for type of care effects was found (Finet et al., 2018). Still another possible explanation is that the initial differential effects of type of pre-adoption care on intellectual abilities may have disappeared because of a ceiling effect, as both the post-institutionalized and the post-foster children seemed to have reached their full intellectual potential at Time 3 (i.e., both groups had above-average IQ scores).

As an aside, although we did not have hypotheses concerning associations between type of pre-adoption care and parenting, it is interesting to note that parents of the postinstitutionalized children scored lower on Time 1 supportive presence than parents of the post-foster children. This effect was not maintained at the following two time points. It seems likely that this finding was due to Type I error. However, another possible, though speculative, explanation for this effect could be that the post-institutionalized children may have been more dysregulated soon after adoption than the post-foster children, which may have elicited somewhat less supportive parenting.

\section{Buffering Effect of Parental Sensitivity}

The findings concerning the remarkable progress in cognitive development of the children in the current sample might indicate that the adoptive family had a protective effect on their cognitive functioning. However, contrary to theory and evidence on the link between parenting and cognitive functioning in non-adopted children (e.g., Eisenberg et al, 2005; 
Fay-Stammbach et al, 2014; Mackintosh, 1998; Spera, 2005), the correlation analyses revealed that there was only one significant association between the two indicators of sensitive parenting and cognitive functioning. Higher supportive presence was associated with higher fluid intelligence, which suggests that supportive parenting might play a role in post-adoption recovery in intellectual functioning. Nonetheless, because the strength of this association was weak and because the associations between sensitive parenting and the other cognitive outcomes were non-significant, more research is needed in order to be able to draw firmer conclusions concerning the beneficial effects of sensitive parenting.

Also, it is important to note that the relative lack of significant associations between our parenting measures and the other indicators of cognitive development does not necessarily imply that parenting did not matter for these aspects of cognitive development, as it might be that other parenting dimensions that were not included in the current analyses (e.g., cognitive stimulating parenting; Fay-Stammbach et al., 2014) impacted cognitive development. Hence, before drawing practical implications from our finding, more research is needed in which multiple parenting dimensions are assessed. Besides it is plausible that variations in our parenting variables were too small to contribute to variability in the children's cognitive outcomes over and above the effects of the drastic shift in caregiving environment that takes place following adoption (e.g., Kumsta et al., 2015). Nonetheless, it is also possible that almost no direct effects of sensitive parenting were found because in the transition to middle childhood the effects of environmental influences on cognitive functioning decrease, whereas the influence of genetic factors increases (Bouchard, 2013; Davis, Haworth, \& Plomin, 2009).

These explanations (concerning the potential role of other parenting dimensions and concerning the increased evidence for heritability of cognitive functioning as children get older) may also explain why we found no support for our hypothesis concerning the buffering 
effect of parenting in the association between type of care and cognitive functioning. We thus found little evidence for the risk and resilience model on which we based on our study. This contradicts previous adoption studies which found support for the risk and resilience framework (e.g., Kriebel \& Wentzel, 2011). Hence, more studies are needed to investigate whether different findings are found in different samples, and to investigate other familyrelated or child-related factors that may explain variability in adopted children's cognitive development. Nonetheless, our results contribute to the literature showing the impressive catch-up in adopted children's cognitive functioning following exposure to more prosperous environments.

\section{Limitations}

Some limitations should be taken into account when interpreting the findings of this study. First, our study had a relatively small sample size which might have reduced the power to detect significant interaction effects, especially given the large number of tests we performed. Furthermore, the sample size was further reduced because missing data were listwise deleted. Despite this, we consider it a strength of our study that drop-out over the course of the study was relatively low with $94.6 \%$ of families still participating at Time 3 . Second, information on type of pre-adoption care was obtained through parent-report. It is possible that this information is not completely reliable, because parents often receive only limited and sometimes inaccurate information about their child's pre-adoption experiences (Juffer et al., 2011). This might have obscured potential effects of type of pre-adoption care and as such might have made it more difficult to find potential buffering effects of adoptive parenting. Hence, caution is warranted in interpreting the non-significant long-term effects of type of pre-adoption care. Moreover, selection bias both with respect to which children were placed for adoption as well as with respect to which children received institutional or foster care prior to adoption might have biased our results. Nonetheless, selection bias is a common 
limitation of adoption studies, and we consider it a strength of our study that we obtained information about children's pre-adoption living arrangement, because this information is often lacking in international adoption studies. Third, potential long-term effects of adverse pre-adoption experiences might have been attenuated because we merely examined the effects of type of pre-adoption care, without taking into account the variability in the quality of care offered by different institutions and by different foster families. Fourth, although a strength of our study is that we assessed different indicators of cognitive functioning, we only included two broad cognitive abilities in our assessment of intellectual functioning, and only two components of executive functioning. Because different cognitive abilities and different components of executive functioning may be differentially affected by adverse experiences and parenting, we do not know whether the findings of our study can be generalized to other aspects of intellectual and executive functioning.

\section{Conclusion}

In sum, results of the third time point of the longitudinal CAN study indicated that although the adopted children showed significant delays in intellectual functioning in the first months after adoption, they showed remarkable recovery in intellectual functioning 9 years later. Moreover, they showed above-average intellectual functioning and did not lag behind in school achievement compared to non-adopted children at the age of 10 years. These findings are noteworthy given the importance of cognitive functioning for future success and wellbeing in life (e.g., Mischel et al., 2010; Moffitt, Poulton, \& Caspi, 2013). We conclude that adoption implies both risk and protective factors. Pre-adoption risks (e.g., separations and neglect) appear to contribute to initial delays, whereas a longer stay in a usually nurturing adoptive family seems to provide a protective factor and contributes to children's recovery. Our outcomes also suggest that although adopted children's initial cognitive delays may 
differ in severity, the generally improved circumstances after adoption may offer them ample opportunities for complete catch-up in the cognitive domain.

We found that the type of care that children received prior to adoption was not related to intellectual functioning, school achievement, executive problems solving and response inhibition at the age of 10 . It is conceivable that, contrary to the assessments in infancy, type of pre-adoption care was no longer associated with intellectual functioning because of a ceiling effect, as both the post-institutionalized and the post-foster children seemed to have reached their full cognitive potential. Finally, we found no evidence for interactions between type of pre-adoption care and parental sensitivity in the prediction of the assessed domains of cognitive development. Despite this, the results concerning the remarkable recovery and catch-up in the post-institutionalized and post-foster children's cognitive functioning at age 10 , points to the children's plasticity and resilience to overcome initial delays in cognitive functioning. In line with previous adoption studies (Juffer, \& Van IJzendoorn, 2009), we can conclude that adoption can be seen as a successful intervention for children who cannot be raised by their birth family. 


\section{References}

Ainsworth, M. D. S., Blehar, M. C., Waters, E., \& Wall, S. (1978). Patterns of attachment: A psychological study of the strange situation. Hillsdale, NJ: Erlbaum.

Alfonso, V. C., Flanagan, D. P., \& Radwan, S. (2005). The impact of the Cattell-HornCarroll theory on test development and interpretation of cognitive and academic abilities. In D. P. Flanagan \& P. L. Harrison (Eds.), Contemporary intellectual assessment: Theories, tests and issues (2nd ed., pp. 185-202). New York: Guilford.

Barroso, R., Barbosa-Ducharne, M., Coelho, V., Costa, I.-S., \& Silva, A. (2017). Psychological adjustment in intercountry and domestic adopted adolescents: A systematic review. Child and Adolescent Social Work Journal, 34(5), 399-418. https://doi.org/10.1007/s10560-016-0485-X

Bartels, M., Rietveld, M. J. H., Van Baal, G. C. M., \& Boomsma, D. I. (2002). Heritability of educational achievement in 12-year-olds and the overlap with cognitive ability. Twin Research and Human Genetics, 5(6), 544-553. https://doi.org/10.1375/twin.5.6.544

Benzies, K., \& Mychasiuk, R. (2009). Fostering family resiliency: A review of the key protective factors. Child and Family Social Work, 14(1), 103-114. https://oi.org/10.1111/j.1365-2206.2008.00586.x

Berg, W. K., \& Byrd, D. L. (2002). The Tower of London Spatial Problem-Solving Task: Enhancing clinical and research implementation. Journal of Clinical and Experimental Neuropsychology, 24(5), 586-604. https://doi.org/10.1076/jcen.24.5.586.1006

Bernier, A., Carlson, S. M., \& Whipple, N. (2010). From external regulation to selfregulation: Early parenting precursors of young children's executive functioning. Child Development, 81(1), 326-339. https//doi.org/10.1111/j.1467-8624.2009.01397.x

Bouchard, T. J. (2013). The Wilson Effect: The increase in heritability of IQ with age. Twin Research and Human Genetics, 16(5), 923-930. https://doi.org/10.1017/thg.2013.54 
Bowlby, J. (1982). Attachment and loss: Vol. 1. Attachment (2nd ed.). New York, NY: Basic Books.

Bruce, J., Tarullo, A. R., \& Gunnar, M. R. (2009). Disinhibited social behavior among internationally adopted children. Development and Psychopathology, 21(1), 157-171. https://oi.org/10.1017/S0954579409000108

Cabrera, N. J., Shannon, J. D., \& Tamis-Lemonda, C. (2007). Fathers' influence on their children's cognitive and emotional development: From toddlers to pre-K. Applied Development Science, 11(4), 208-213. https//doi.org/10.1080/10888690701762100

Cattell, R. B. (1971). Abilities: Their structure, growth and action. Boston, MA: HoughtonMifflin.

Cohen, N. J., Lojkasek, M., Zadeh, Z. Y., Pugliese, M., \& Kiefer, H. (2008). Children adopted from China: A prospective study of their growth and development. Journal of Child Psychology and Psychiatry and Allied Disciplines, 49(4), 458-468. https://oi.org/10.1111/j.1469-7610.2007.01853.x

Congdon, E., Mumford, J. A., Cohen, J. R., Galvan, A., Canli, T., \& Poldrack, R. A. (2012). Measurement and reliability of response inhibition. Frontiers in Psychology, 3, 1-10. https://oi.org/10.3389/fpsyg.2012.00037

Culbertson, W. C., \& Zillmer, E. A. (1998). The Tower of London DX: A standardized approach to assessing executive functioning in children. Archives of Clinical Neuropsychology, 13(3), 285-301. https://doi.org/10.1016/S0887-6177(97)00033-4

Dalen, M., \& Rygvold, A. L. (2006). Educational achievement in adopted children from China. Adoption Quarterly, 9(4), 45-58. https://doi.org/10.1300/J145v09n04_03

Davis, O. S. P., Haworth, C. M. A., \& Plomin, R. (2009). Dramatic increase in heritability of cognitive development from early to middle childhood: An 8-year longitudinal study of 8700 pairs of twins. Psychological Science, 20(10), 1301-1308. 
https://oi.org/10.1111/j.1467-9280.2009.02433.x.

Delcenserie, A., Genesee, F., \& Gauthier, K. (2013). Language abilities of internationally adopted children from China during the early school years: Evidence for early age effects? Applied Psycholinguistics, 34(3), 541-568. https://doi.org/10.1017/S0142716411000865

Downer, J. T., \& Pianta, R. C. (2006). Academic and cognitive functioning in first grade: Associations with earlier home and child care predictors and with concurrent home and classroom experiences. School Psychology Review, 35(1), 11-30. https://oi.org/10.1046/j.1467-8624.2003.00629.x

Dozier, M., Kaufman, J., Kobak, R., O'Connor, T. G., Sagi-Schwartz, A., Scott, S., . . Zeanah, C. H. (2014). Consensus statement on group care for children and adolescents: A statement of policy of the American Orthopsychiatric Association. American Journal of Orthopsychiatry, 84, 219-225. doi:10.1037/ort0000005

Egeland, B., Erickson, M. F., Clemenhagen-Moon, J., Hiester, M. K., \& Korfmacher, J. (1990). 24 months tools coding manual. Project STEEP-revised 1990. From motherchild project scales-1978. Unpublished manuscript, University of Minnesota, Minneapolis.

Eisenberg, N., Zhou, Q., Spinrad, T. L., Valiente, C., Fabes, R. A., \& Liew, J. (2005). Relations among positive parenting, children's effortful control, and externalizing problems: A three-wave longitudinal study. Child Development, 76(5), 1055-1071. https://oi.org/10.1111/j.1467-8624.2005.00897.x

Erickson, M. F., Sroufe, L. A., \& Egeland, B. (1985). VI. The relationship between quality of attachment and behavior problems in preschool in a high-risk sample. Monographs of the Society for Research in Child Development, 50(1/2), 147-166. https://oi.org/10.2307/3333831 
Fay-Stammbach, T., Hawes, D. J., \& Meredith, P. (2014). Parenting influences on executive function in early childhood: A review. Child Development Perspectives, 8(4), 258-264. https://doi.org/10.1111/cdep.12095

Finet, C., Vermeer, H. J., Juffer, F., \& Bosmans, G. (2018). Behavioral adjustment of Chinese adoptees: The role of pre-adoption experiences. Children and Youth Services Review, 86, 226-235. https://doi.org/10.1016/j.childyouth.2018.01.029

Finet, C., Vermeer, H. J., Juffer, F., Bijttebier, P., \& Bosmans, G. (2019). Adopted children's behavioral adjustment over time: Interactions between pre-adoption experiences and adoptive parenting. The Journal of Early Adolescence, 1-27. https://doi.org/10.1177/0272431619858408

Finet, C., Vermeer, H. J., Juffer, F., Bosmans, G., \& Bijttebier, P. (2016). Children's catch-up in cognitive competence after adoption. In F. Genesee \& A. Delcenserie (Eds.), [TiLAR 18] Starting Over - The Language Development in Internationally Adopted Children (pp. 39-64). Amsterdam: John Benjamins Publishing Company. https://doi.org/10.1075/tilar.18.03 fin

Flynn, J. R. (1987). Massive IQ gains in 14 nations: What IQ tests really measure. Psychological Bulletin, 101(2), 171-191. https://doi.org/10.1037/0033-2909.101.2.171

Frydman, M., \& Lynn, R. (1989). The intelligence of Korean children adopted in Belgium. Personality and Individual Differences, 10(12), 1323-1325. https://doi.org/10.1016/0191-8869(89)90246-8

Groza, V., Ryan, S. D., \& Thomas, S. (2008). Institutionalization, Romanian adoptions and executive functioning. Child and Adolescent Social Work Journal, 25(3), 185-204. https:/doi.org/10.1007/s10560-008-0120-6

Gunnar, M. R., Bruce, J., \& Grotevant, H. D. (2000). International adoption of institutionally reared children: Research and policy. Development and Psychopathology, 12(4), 677- 
693. https://doi.org/10.1017/S0954579400004077

Hayes, A. F. (2013). Introduction to mediation, moderation, and conditional process analysis: A regression-based approach. New York, NY: The Guilford Press.

Hesketh, T., Zhou, X., \& Wang, Y. (2015). The end of the one-child policy: Lasting implications for China. JAMA, 314(24), 2619-2620.

https://doi.org/10.1001/jama.2015.16279

Juffer, F., Palacios, J., Le Mare, L., Sonuga-Barke, E. J. S., Tieman, W., BakermansKranenburg, M. J., .. Verhulst, F. C. (2011). II. Development of adopted children with histories of early adversity. Monographs of the Society for Research in Child Development, 76(4), 31-61. https://doi.org/10.1111/j.1540-5834.2011.00627.x

Juffer, F., Van den Dries, L., Finet, C., \& Vermeer, H. J. (2015). Bindung und kognitive sowie motorische Entwicklung in den ersten fünf Jahren nach der Adoption: Ein review über international adoptierte Kinder aus China [Attachment and cognitive and motor development in the first years after adoption: Review of studies]. Praxis Der Kinderpsychologie Und Kinderpsychiatrie, 64(10), 774-792. https://doi.org/10.13109/prkk.2015.64.10.774

Juffer, F., \& Van IJzendoorn, M. H. (2009). International adoption comes of age: Development of international adoptees from a longitudinal and meta-analytical perspective. In G. M. Wrobel \& E. Neil (Eds.), International Advances in Adoption Research for Practice (pp. 169-192). Chichester, UK: Wiley-Blackwell.

Katzenstein, J. M., LeJeune, B. C., \& Johnson, K. E. (2016). The role of parenting and family factors in the developmental catch-up for children adopted internationally. Adoption Quarterly, 19(3), 224-236. https://doi.org/10.1080/10926755.2016.1201710

Kort, W., Schittekatte, M., Dekker, P. H., Verhaeghe, P., Compaan, E. L., Bosmans, M., \& Vermeir, G. (2005). WISC-III NL Wechsler Intelligence Scale for Children. Derde Editie 
NL. Handleiding en Verantwoording. [Dutch version of the WISC-III]. Amsterdam:

Harcourt Test Publishers/Nederlands Instituut voor Psychologen.

Kriebel, D. K., \& Wentzel, K. (2011). Parenting as a moderator of cumulative risk for behavioral competence in adopted children. Adoption Quarterly, 14(1), 37-60. https://doi.org/10.1080/10926755.2011.557945

Kumsta, R., Kreppner, J., Kennedy, M., Knights, N., Rutter, M., \& Sonuga-Barke, E. J. S. (2015). Psychological consequences of early global deprivation an overview of findings from the English \& Romanian Adoptees Study. European Psychologist, 20(2), 138-151. https://doi.org/10.1027/1016-9040/a000227

Landgren, M., Svensson, L., Strömland, K., \& Grönlund, M. A. (2010). Prenatal alcohol exposure and neurodevelopmental disorders in children adopted from Eastern Europe. Pediatrics, 125(5), e1178-e1185. https://doi.org/10.1542/peds.2009-0712

Landry, S. H., Smith, K. E., Swank, P. R., Assel, M. A., \& Vellet, S. (2001). Does early responsive parenting have a special importance for children's development or is consistency across early childhood necessary? Developmental Psychology, 37(3), 387403. https:/doi.org/10.1037/0012-1649.37.3.387

Logan, G. D., Van Zandt, T., Verbruggen, F., \& Wagenmakers, E. J. (2014). On the ability to inhibit thought and action: General and special theories of an act of control. Psychological Review, 121(1), 66-95. https://doi.org/10.1037/a0035230

Loman, M. M., \& Gunnar, M. R. (2010). Early experience and the development of stress reactivity and regulation in children. Neuroscience and Biobehavioral Reviews, 34(6), 867-876. https://doi.org/10.1016/j.neubiorev.2009.05.007

Loman, M. M., Wiik, K. L., Frenn, K. A., Pollak, S. D., \& Gunnar, M. R. (2009). Postinstitutionalized children's development: Growth, cognitive, and language outcomes. Journal of Developmental and Behavioral Pediatrics, 30(5), 426-434. 
https://doi.org/10.1097/DBP.0b013e3181b1 fd08

Lugo-gil, J., \& Tamis-lemonda, C. S. (2008). Family Resources and Parenting Quality: Links to Children $\hat{\mathrm{a}} \mathrm{T}^{\mathrm{TM}} \mathrm{s}$ Cognitive Development across the First 3 Years. Child Development, 79(4), 1065-1085.

Mackintosh, N. J. (1998). IQ and human intelligence. New York, United States: Oxford University Press.

Masten, A. S. (2001). Ordinary Magic: Resilience processes in development. American Psyhologist, 56(3), 227-238. https://doi.org/10.1037//0003-066X.56.3.227

Merz, E. C., Harlé, K. M., Noble, K. G., \& McCall, R. B. (2016). Executive function in previously institutionalized children. Child Development, 10(2), 105-110. https://doi.org/10.1111/cdep.12170

Miller, L. C., Chan, W., Comfort, K., \& Tirella, L. (2005). Health of children adopted from Guatemala: Comparison of orphanage and foster care. Pediatrics, 115(6), e710-e717. https://doi.org/10.1542/peds.2004-2359

Mischel, W., Ayduk, O., Berman, M. G., Casey, B. J., Gotlib, I. H., Jonides, J., ... Shoda, Y. (2010). "Willpower" over the life span: Decomposing self-regulation. Social Cognitive and Affective Neuroscience, 6(2), 252-256. https:/doi.org/10.1093/scan/nsq081

Moffitt, T. E., Poulton, R., \& Caspi, A. (2013). Lifelong impact of early self-control. American Scientist, 101(5), 352-359. https://doi.org/10.1511/2013.104.352

Nelson, C. A., Bos, K. J., Gunnar, M. R., \& Sonuga-Barke, E. J. S. (2011). V. The neurobiological toll of early human deprivation. Monographs of the Society for Research in Child Development, 76(4), 127-146. https://doi.org/10.1111/j.15405834.2011.00630.x

O’Connor, T. G., Rutter, M., Beckett, C., Keaveney, L., \& Kreppner, J. M. (2000). The effects of global severe privation on cognitive competence: Extension and longitudinal 
follow-up. Child Development, 71(2), 376-390. https://doi.org/10.1111/14678624.00151

Odenstad, A., Hjern, A., Lindblad, F., Rasmussen, F., Vinnerljung, B., \& Dalen, M. (2008). Does age at adoption and geographic origin matter? A national cohort study of cognitive test performance in adult inter-country adoptees. Psychological Medicine, 38(12), 18031814. https:/doi.org/10.1017/S0033291708002766

Palacios, J., Adroher, S., Brodzinsky, D.M., Grotevant, H.D., Johnson, D.E., Juffer, F., ..., \& Tarren-Sweeney, M. (2019). Adoption in the service of child protection: An international interdisciplinary perspective. Psychology, Public Policy, and Law, 25(2), 57-72.

Palacios, J., \& Brodzinsky, D. M. (2010). Adoption research: Trends, topics, outcomes. International Journal of Behavioral Development, 34(3), 270-284. https://doi.org/10.1177/0165025410362837

Pietschnig, J., \& Voracek, M. (2015). One century of global IQ gains: A formal meta-analysis of the Flynn Effect (1909-2013). Perspectives on Psychological Science, 10(3), 282306. https $/ /$ doi.org/10.1177/1745691615577701

Plug, E., \& Vijverberg, W. (2003). Schooling, family background, and adoption: is it nature or nurture? Journal of Political Economy, 111(3), 611-641.

Pollak, S. D., Nelson, C. A., Schlaak, M. F., Roeber, B. J., Wewerka, S. S., Wiik, K. L., ... Gunnar, M. R. (2010). Neurodevelopmental effects of early deprivation in postinstitutionalized children. Child Development, 81(1), 224-236. https://doi.org/10.1111/j.1467-8624.2009.01391.x

Pomerleau, A., Malcuit, G., Chicoine, J.-F., Séguin, R., Belhumeur, C., Germain, P., ... Jéliu, G. (2005). Health status, cognitive and motor development of young children adopted from China, East Asia, and Russia across the first 6 months after adoption. International 
Journal of Behavioral Development, 29(5), 445-457.

https://doi.org/10.1080/01650250500206257

Rice, J. L., Jackson, A., Mahoney, E. E., \& Tan, T. X. (2016). Pre-adoption stress, adversity and later development in IA children. In F. Genesee \& A. Delcenserie (Eds.), Starting Over - The Language Development in Internationally-Adopted Children (1st ed., pp. 1936). Amsterdam / Philadelphia: John Benjamins Publishing Company. https://oi.org/10.1075/tilar.18.02ric

Rutter, M. (1987). Psychosocial resilience and protective mechanisms. American Journal of Orthopsychiatry, 57(3), 316-331.

Rutter, M., \& the ERA study team. (1998). Developmental catch-up, and deficit, following adoption after severe global early privation. Journal of Child Psychology and Psychiatry, 39(4), 465-476.

Ryan, R. M., Martin, A., \& Brooks-Gunn, J. (2006). Is one good parent good enough? Patterns of mother and father parenting and child cognitive outcomes at 24 and 36 months. Parenting: Science and Practice, 6(2-3), 211-228.

https://doi.org/10.1080/15295192.2006.9681306

Sattler, J. M. (1992). Assessment of children: WISC-III and WPPSI-R supplement. San Diego, CA: Author.

Selman, P. (2015). Intercountry adoption of children from Asia in the twenty-first century. Children's Geographies, 13(3), 312-327. https://doi.org/10.1080/14733285.2015.972657

Smith, C., Cossette, L., Melançon, F., Beauvais-Dubois, C., Smolla, N., Gagnon-Oosterwaal, N., .. Bégin, J. (2018). Behavior problems in adolescence among international adoptees, pre-adoption adversity, and parenting stress. Journal of Applied Developmental Psychology, 57, 53-61. https://doi.org/10.1016/j.appdev.2018.04.005 
Spera, C. (2005). A review of the relationship among parenting practices, parenting styles, and adolescent school achievement. Educational Psychology Review, 17(2), 125-146. https://doi.org/10.1007/s10648-005-3950-1

Sroufe, L. A., Coffino, B., \& Carlson, E. A. (2010). Conceptualizing the role of early experience: Lessons from the Minnesota longitudinal study. Developmental Review, 30(1), 36-51. https://doi.org/10.1016/j.dr.2009.12.002

Stams, G. J. J. M., Juffer, F., Rispens, J., \& Hoksbergen, R. A. C. (2000). The development and adjustment of 7-year-old children adopted in infancy. The Journal of Child Psychology and Psychiatry and Allied Disciplines, 41(8), 1025-1037. https://doi.org/10.1017/S0021963099006344

Stams, G. J. J. M., Juffer, F., \& Van IJzendoorn, M. H. (2002). Maternal sensitivity, infant attachment, and temperament in early childhood predict adjustment in middle childhood: The case of adopted children and their biologically unrelated parents. Developmental Psychology, 38(5), 806-821. https://doi.org/10.1037/0012-1649.38.5.806

Tellegen, P. J., \& Laros, J. A. (2011). Snijders-Oomen Niet-verbale intelligentietest SON-R 640. I. Verantwoording. Amsterdam, the Netherlands: Hogrefe uitgevers.

Tottenham, N. (2012). Risk and developmental heterogneity in previously-institutionalized children. Journal of Adolescent Health, 51(2), S29-S33. https://doi.org/10.1016/j.jadohealth.2012.04.004

Trahan, L. ., Stuebing, K. K., Fletcher, J. M., \& Hiscock, M. K. (2014). Flynn effect: A metaanalysis. Psychological Bulletin, 140(5), 1-12. https://doi.org/10.1037/a0037173. The

Van den Dries, L., Juffer, F., Van IJzendoorn, M. H., \& Bakermans-Kranenburg, M. J. (2010). Infants' physical and cognitive development after international adoption from foster care or institutions in China. Journal of Developmental and Behavioral Pediatrics, 31(2), 144-150. https//doi.org/10.1097/DBP.0b013e3181cdaa3a 
Van den Dries, L., Juffer, F., Van IJzendoorn, M. H., Bakermans-Kranenburg, M. J., \& Alink, L. R. A. (2012). Infants' responsiveness, attachment, and indiscriminate friendliness after international adoption from institutions or foster care in China: Application of Emotional Availability Scales to adoptive families. Development and Psychopathology, 24(1), 49-64. https//doi.org/10.1017/S0954579411000654

Van der Meulen, B. F., Ruiter, S. A. J., Lutje Spelberg, H. C., \& Smrkovsky, M. (2004). BSID-II-NL, deel I: praktische handleiding [BSID-II-NL, Part I: Practical Manual] (2nd ed.). Amsterdam, the Netherlands: Harcourt Test Publishers.

Van IJzendoorn, M. H., Juffer, F., \& Klein Poelhuis, C. W. (2005). Adoption and cognitive development: A meta-analytic comparison of adopted and nonadopted children's IQ and school performance. Psychological Bulletin, 131(2), 301-316. https://doi.org/10.1037/0033-2909.131.2.301

Van IJzendoorn, M. H., Palacios, J., Sonuga-barke, E. J. S., Gunnar, M. R., Vorria, P., McCall, R. B., ... Juffer, F. (2011). I. Children in institutional care: Delayed development and resilience. Monographs of the Society for Research in Child Development, 76(4), 8-30. https://doi.org/10.1111/j.1540-5834.2011.00626.x van Londen, W. M., Juffer, F., \& Van IJzendoorn, M. H. (2007). Attachment, cognitive, and motor development in adopted children: Short-term outcomes after international adoption. Journal of Pediatric Psychology, 32(10), 1249-1258. https://oi.org/10.1093/jpepsy/jsm062

Verbruggen, F., Chambers, C. D., \& Logan, G. D. (2013). Fictitious inhibitory differences: How skewness and slowing distort the estimation of stopping latencies. Psychological Science, 24(3), 352-362. https://doi.org/10.1177/0956797612457390

Verbruggen, F., \& Logan, G. D. (2015). Evidence for capacity sharing when stopping. Cognition, 142, 81-95. https://doi.org/10.1016/j.cognition.2015.05.014 
Verbruggen, F., Logan, G. D., \& Stevens, M. A. (2008). STOP-IT: Windows executable software for the stop-signal paradigm. Behavior Research Methods, 40(2), 479-483. https://oi.org/10.3758/BRM.40.2.479

Vorria, P., Papaligoura, Z., Sarafidou, J., Kopakaki, M., Dunn, J., Van IJzendoorn, M. H., \& Kontopoulou, A. (2006). The development of adopted children after institutional care: A follow-up study. Journal of Child Psychology and Psychiatry, 47(12), 1246-1253. https://oi.org/10.1111/j.1469-7610.2006.01666.x

Wechsler, D. (1991). Manual for the Wechsler Intelligence Scale for Children - Third Edition (WISC-III). San Antonio TX: The Psychological Corporation.

Welsh, J. A., \& Viana, A. G. (2012). Developmental outcomes of internationally adopted children. Adoption Quarterly, 15(4), 241-264. https://doi.org/10.1080/10926755.2012.731029

Whitten, K. L., \& Weaver, S. R. (2010). Adoptive family relationships and healthy adolescent development: A risk and resilience analysis. Adoption Quarterly, 13(3), 209226. https:/doi.org/10.1080/10926755.2010.524873

Wilson, S. L., Weaver, T. L., Cradock, M. M., \& Kuebli, J. E. (2008). A preliminary study of the cognitive and motor skills acquisition of young international adoptees. Children and Youth Services Review, 30(5), 585-596.

https://doi.org/10.1016/j.childyouth.2007.10.017

Zhou, Q., Chen, S. H., \& Main, A. (2012). Commonalities and differences in the research on children's effortful control and executive function: A call for an integrated model of self-regulation. Child Development Perspectives, 6(2), 112-121. https://oi.org/10.1111/j.1750-8606.2011.00176.x 


\section{Footnotes}

${ }^{1}$ To explore the possibility that effects of type of pre-adoption might have been attenuated by differences in quality of care among different institutions and among different foster families, supplementary analyses were performed in which type of pre-adoption care was replaced by an early deprivation composite (sum of subnutrition, physical neglect, socioemotional neglect, abuse). No significant associations between early deprivation and the cognitive outcomes were found ( $p$ 's ranging from .433 to .910). More detailed results can be obtained on request.

${ }^{2}$ Supplementary interaction analyses in which type of pre-adoption care was replaced by early deprivation also did not yield any significant early deprivation x parenting interactions in the prediction of the Time 3 outcomes using the Bonferonni corrected significance level of .004 ( $p$ 's ranging from .021 to .938). More detailed results can be obtained on request. 
Table 1

Descriptives of model variables (prior to transformations)

\begin{tabular}{|c|c|c|c|c|c|c|c|c|c|}
\hline & \multicolumn{6}{|c|}{ Type of pre-adoption care } & \multirow{2}{*}{\multicolumn{3}{|c|}{ Total sample $(N=92)$}} \\
\hline & \multicolumn{3}{|c|}{ Post-institutionalized $(N=50)$} & \multicolumn{3}{|c|}{ Post-foster $(N=42)$} & & & \\
\hline & $N$ & $M$ & $S D$ & $N$ & $M$ & $S D$ & $N$ & $M$ & $S D$ \\
\hline T1 Supportive presence & 49 & 4.64 & 1.48 & 42 & $5.54^{\mathrm{b}}$ & 1.06 & 91 & 5.06 & 1.37 \\
\hline T2 Supportive presence & 49 & 5.01 & 1.58 & 42 & 4.89 & 1.48 & 91 & 4.95 & 1.53 \\
\hline T3 Supportive presence & 46 & 4.16 & 1.24 & 41 & 4.14 & 1.25 & 87 & 4.15 & 1.23 \\
\hline T1 Intrusiveness & 49 & 3.08 & 1.36 & 42 & 2.66 & 1.25 & 91 & 2.88 & 1.32 \\
\hline T2 Intrusiveness & 49 & 2.89 & 1.39 & 42 & 3.33 & 1.45 & 91 & 3.10 & 1.43 \\
\hline T3 Intrusiveness & 46 & 4.18 & 1.50 & 41 & 4.76 & 1.24 & 87 & 4.45 & 1.40 \\
\hline T1 intellectual abilities & 50 & 74.04 & 18.41 & 42 & $84.40^{\mathrm{b}}$ & 17.62 & 92 & 78.77 & 18.69 \\
\hline T2 intellectual abilities & 50 & 84.38 & 20.01 & 42 & 92.26 & 17.83 & 92 & 87.98 & 19.35 \\
\hline T3 Crystallized intelligence & 46 & 111.37 & 12.60 & 41 & 110.49 & 11.85 & 87 & 110.95 & 12.19 \\
\hline T3 Fluid intelligence & 46 & 108.98 & 16.33 & 41 & 109.27 & 15.96 & 87 & 109.11 & 16.06 \\
\hline T3 Math performance ${ }^{c}$ & 48 & 2.52 & 1.37 & 41 & 2.66 & 1.46 & 89 & 2.58 & 1.40 \\
\hline T3 Reading comprehension ${ }^{\mathrm{c}}$ & 48 & 2.29 & 1.38 & 41 & 2.29 & 1.25 & 89 & 2.29 & 1.32 \\
\hline T3 TOL problem-solving efficiency ${ }^{\mathrm{d}}$ & 46 & 48.37 & 16.06 & 41 & 49.85 & 18.86 & 87 & 49.07 & 17.35 \\
\hline T3 Response inhibition ${ }^{\mathrm{c}, \mathrm{e}}$ & 39 & 264.90 & 79.33 & 36 & 251.34 & 53.34 & 75 & 258.39 & 68.07 \\
\hline
\end{tabular}

Note. ${ }^{\mathrm{a}}$ significant difference between the post-institutionalized and the post-foster children at $p<.05 .{ }^{\mathrm{b}}$ significant difference between the two

groups at $p<.01 .{ }^{\mathrm{c}}$ original untransformed values. ${ }^{\mathrm{d}}$ higher scores indicate higher move score. ${ }^{\mathrm{e}}$ participants who did not meet the criteria to

compute response inhibition were excluded, higher scores indicate slower response inhibition. 
Table 2

Correlations between Time 1 and Time 2 intellectual abilities, type of pre-adoption care, parenting factor scores and Time 3 cognitive development

\begin{tabular}{|c|c|c|c|c|c|c|c|c|c|c|c|}
\hline & 1 & 2 & 3 & 4 & 5 & 6 & 7 & 8 & 9 & 10 & $\overline{11}$ \\
\hline 1. T1 intellectual abilities & 1 & & & & & & & & & & \\
\hline 2. T2 intellectual abilities & $.65^{* * *}$ & 1 & & & & & & & & & \\
\hline 3. Type of pre-adoption care ${ }^{\mathrm{a}}$ & $.28^{* *}$ & .20 & 1 & & & & & & & & \\
\hline 4. Factor score supportive presence & .00 & .00 & .12 & 1 & & & & & & & \\
\hline 5. Factor score intrusiveness & -.03 & -.03 & .06 & $-.58^{* * *}$ & 1 & & & & & & \\
\hline 6. Crystallized intelligence & .06 & .15 & -.04 & .04 & .06 & 1 & & & & & \\
\hline 7. Fluid intelligence & $.25^{*}$ & .21 & .01 & $.23^{*}$ & -.05 & $.41^{* * *}$ & 1 & & & & \\
\hline 8. Math performance ${ }^{b, c}$ & -.07 & -.13 & .05 & .07 & -.05 & $-.39^{* * *}$ & $-.48^{* * *}$ & 1 & & & \\
\hline 9. Reading comprehension ${ }^{b}, c$ & .01 & -.04 & .00 & .04 & -.06 & $-.45^{* * *}$ & $-.48^{* * *}$ & $.66^{* * *}$ & 1 & & \\
\hline 10. TOL efficiency ${ }^{d}$ & -.09 & -.13 & .04 & -.00 & -.09 & -.11 & $-.31^{* *}$ & $.25^{*}$ & .12 & 1 & \\
\hline 11. Response inhibition ${ }^{\mathrm{b}}$, e & .01 & -.15 & -.10 & -.09 & .06 & .16 & -.05 & .01 & .16 & $.27^{*}$ & 1 \\
\hline
\end{tabular}

Note. TOL efficiency $=\mathrm{TOL}^{\mathrm{DX}}$ problem-solving efficiency. ${ }^{\mathrm{a}} 0=$ institutional care, $1=$ foster care. ${ }^{\mathrm{b}}$ original, untransformed values. ${ }^{\mathrm{c}}$ lower scores indicate higher math performance and reading comprehension. ${ }^{\mathrm{d}}$ Higher scores indicate higher move score. ${ }^{\mathrm{e}}$ participants who did not meet the criteria to compute response inhibition (SSRT) were excluded, higher scores indicate slower response inhibition (higher SSRT).

$* p<.05 . * * p<.01 . * * * p<.001$. 
Table 3

Interactions between type of pre-adoption care and the parenting factor scores in the prediction of cognitive functioning at age 10

\begin{tabular}{lccccccccc}
\hline & \multicolumn{3}{c}{ Factor score supportive presence } & \multicolumn{7}{c}{ Factor score intrusiveness } \\
\cline { 2 - 9 } & $F$ & $d f$ & $p$ & $\Delta R^{2}$ & $F$ & $d f$ & $p$ & $\Delta R^{2}$ \\
\hline Crystallized intelligence & 2.09 & 1,80 & .152 & .03 & 0.85 & 1,80 & .358 & .01 \\
Fluid intelligence & 4.38 & 1,80 & .039 & .05 & 3.53 & 1,80 & .064 & .04 \\
Math performance & 0.29 & 1,79 & .595 & .00 & 0.05 & 1,79 & .821 & .00 \\
Reading comprehension & 0.68 & 1,79 & .413 & .01 & 0.09 & 1,79 & .764 & .00 \\
TOL efficiency & 2.36 & 1,81 & .129 & .03 & 0.17 & 1,81 & .686 & .00 \\
Response inhibition & & & & & & & & & \\
& 2.73 & 1,69 & .103 & .04 & 0.46 & 1,69 & .500 & .01 \\
\hline
\end{tabular}

Note. TOL efficiency $=\mathrm{TOL}^{\mathrm{DX}}$ problem-solving efficiency.

a Participants who did not meet the criteria to compute response inhibition (SSRT) were excluded.

A Bonferroni corrected significance value of .004 was used. 


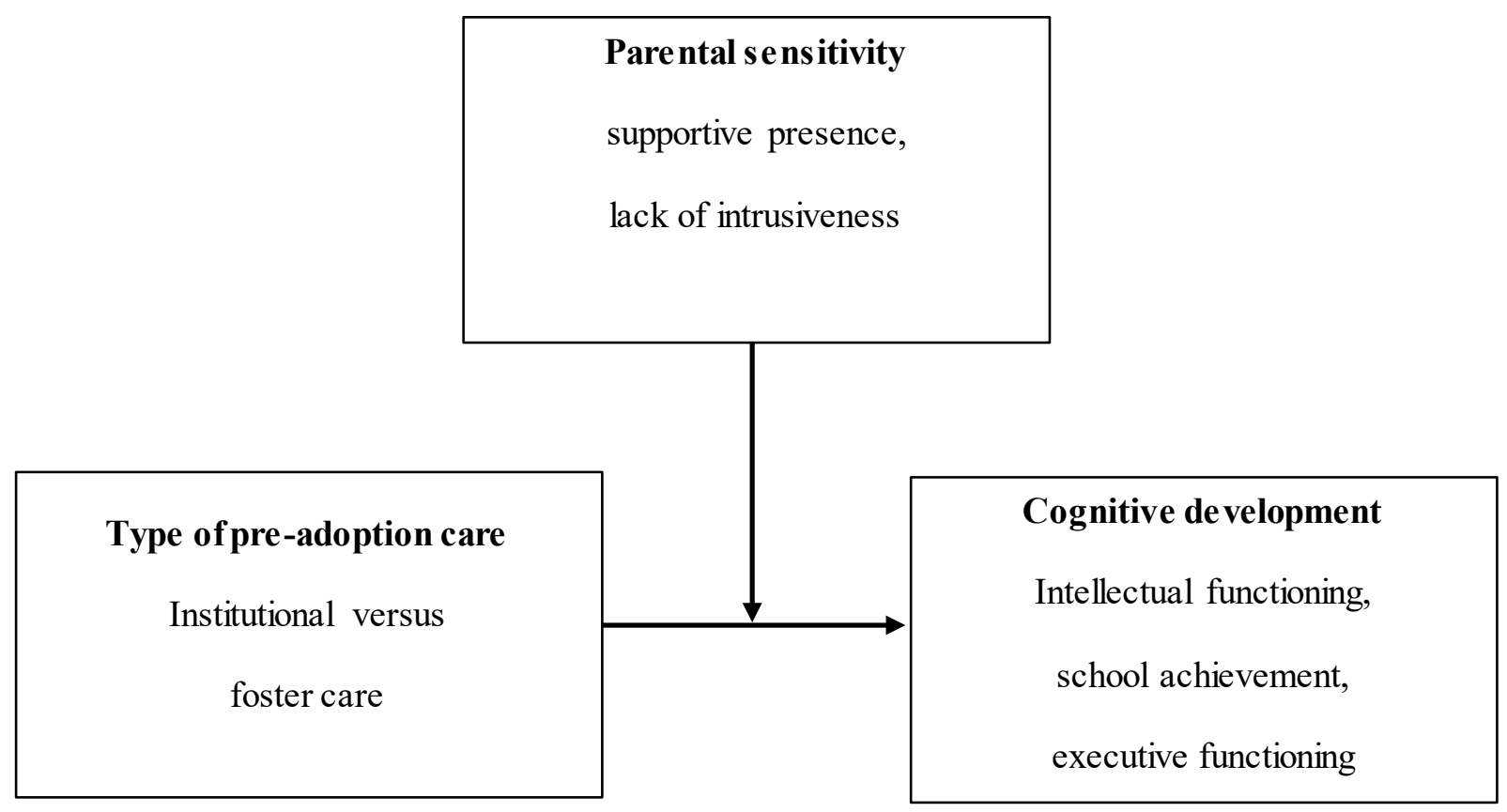

Figure 1. Conceptual model of the interactions tested between type of pre-adoption care and sensitive parenting in the prediction of cognitive development at age 10 . 


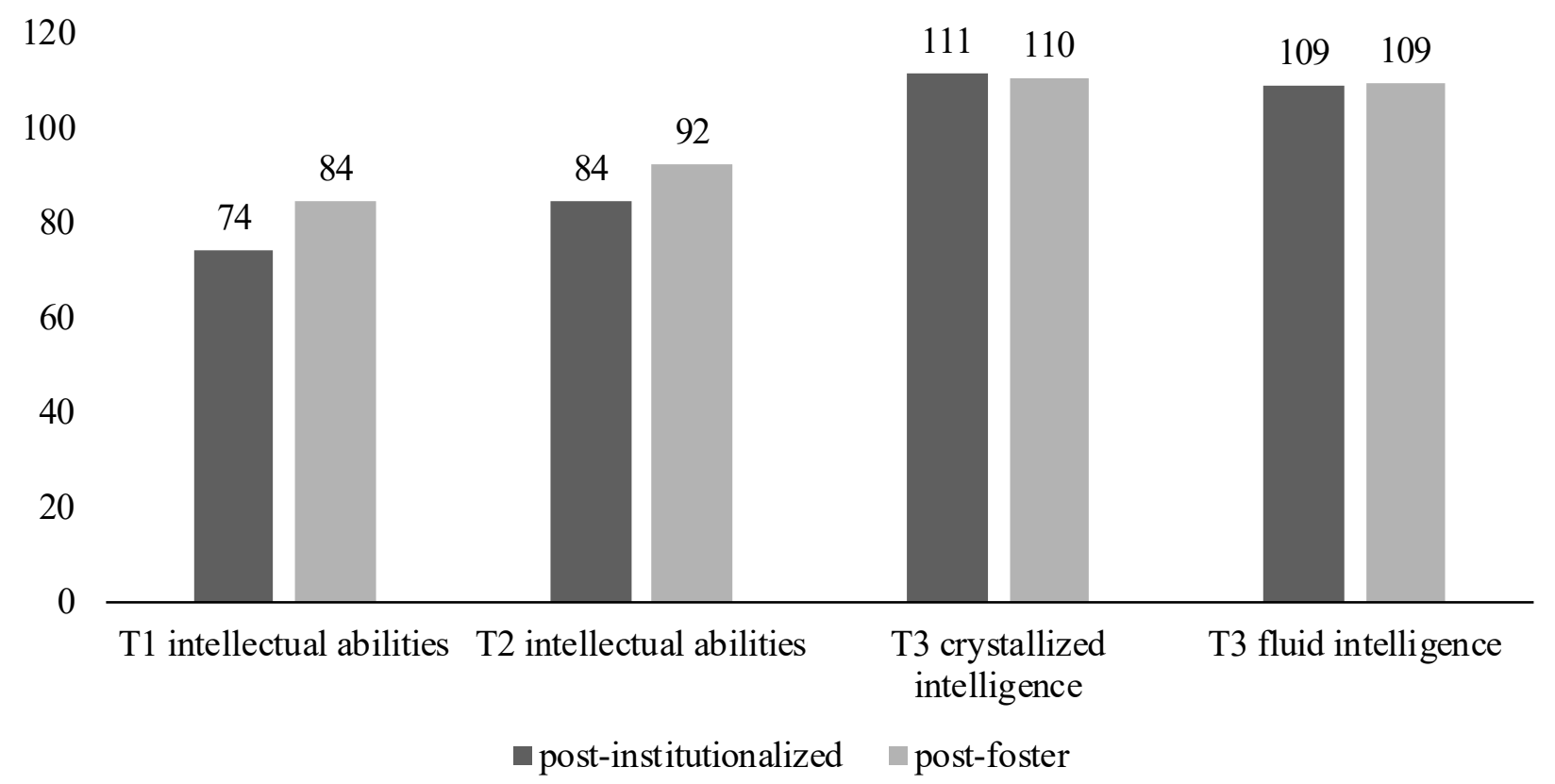

Figure 2. Mean intellectual functioning of the post-institutionalized and the post-foster children at the three time points. 


\section{Footnotes}

${ }^{1}$ To explore the possibility that effects of type of pre-adoption might have been attenuated by differences in quality of care among different institutions and among different foster families, supplementary analyses were performed in which type of pre-adoption care was replaced by an early deprivation composite (sum of subnutrition, physical neglect, socioemotional neglect, abuse). No significant associations between early deprivation and the cognitive outcomes were found ( $p$ 's ranging from .433 to .910). More detailed results can be obtained on request.

${ }^{2}$ Supplementary interaction analyses in which type of pre-adoption care was replaced by early deprivation also did not yield any significant early deprivation x parenting interactions in the prediction of the Time 3 outcomes using the Bonferonni corrected significance level of .004 ( $p$ 's ranging from .021 to .938). More detailed results can be obtained on request. 


\section{Acknowledgements}

We would like to thank the girls and their parents for their generous participation to the CAN study. This research was supported by a grant of the Research Fund KU Leuven [grant number OT/12/043] assigned to Guy Bosmans and Patricia Bijttebier, and by a grant of the Research Foundation Flanders [grant number G.0774.15] assigned to Guy Bosmans. Femmie Juffer is supported by the Chair on Adoption Studies

\section{Role of the funding source}

The sponsor did not play a role in the study design; nor in the collection, analysis and interpretation of data; nor in the writing of the report; nor in the decision to submit the article.

Declaration of interests: none 